Published in final edited form as:

J Cardiovasc Pharmacol. 2018 March ; 71(3): 127-128. doi:10.1097/FJC.0000000000000539.

\title{
LEVOSIMENDAN IN ADVANCED HEART FAILURE: WHERE DO WE STAND?
}

\author{
Antonio Abbate, MD, $\mathrm{PhD}^{1}$ and Benjamin W. Van Tassell, PharmD $^{2}$ \\ 1VCU Pauley Heart Center \\ ${ }^{2}$ Department of Pharmacotherapy and Outcome Sciences, School of Pharmacy - Virginia \\ Commonwealth University, Richmond, VA, Box 980204, 1200 E. Marshall street, Richmond, VA, \\ 23298
}

\begin{abstract}
Heart failure (HF) remains the final common pathway for multiple cardiovascular disorders. As patients progress to advanced stages of the disease (American Heart Association/ American College of Cardiology Stage D), many patients require inotropic support to alleviate symptoms and maintain end-organ perfusion. While these agents can produce rapid symptomatic improvements, prolonged inotropic support has been associated with significant risk of arrhythmias and increased mortality. Increased myocardial $\mathrm{Ca}^{2+}$ transient currents appear to be simultaneously responsible for both the benefits and risks of these inotropic agents. This observation has set stage for the development of novel inotropic agents that are not dependent upon increasing $\mathrm{Ca}^{2+}$ transients.
\end{abstract}

The current issue of the Journal includes a narrative by Altenberger et al. [1] that summarized eight hands-on tutorials at the Heart Failure Association of the European Society of Cardiology annual meeting in Paris on April 30-May 1, 2016, supported by Orion Pharma, the maker of levosimendan, describing the evidence supporting the use of levosimendan as a calcium sensitizing inotrope that would fulfill this need for a safer alternative to traditional calcium mobilizing inotropes. While there may be room for some optimism regarding the unique mechanism of action, paradigm-changing claims of safety and superiority versus traditional inotropes cannot be established by extrapolations of small phase II studies alone. Instead, the burden of proof remains on proponents of levosimendan to provide appropriately designed phase III clinical trials to differentiate levosimendan from traditional inotropes - all of which provide dramatic symptomatic improvement and are relatively safe with short-term use.

As of August 2017, levosimendan is approved for use extensively across the globe, but is not approved for use in the United States. The bulk of the evidence supporting the use of levosimendan can be summarized by a 2012 meta-analysis of 45 randomized clinical trials conducted between 1999-2010 [2] and a recent series of 3 clinical trials that evaluated pulsatile outpatient infusions of levosimendan [3-5]. Conversely, the most concerning evidence against levosimendan may be the historical trend of increased adverse cardiovascular outcomes with prolonged inotropic support, the absence of any stand-alone definitive trial, and the results of two recent levosimendan studies in cardiac surgery patients [6-7]. 
The 2012 meta-analysis reported a significant mortality reductions among levosimendantreated patients versus placebo (risk ratio 0.82 [0.69-0.97], $\mathrm{p}=0.02$ ) or dobutamine (risk ratio 0.68 [0.52-0.88], $\mathrm{p}=0.003$ )[2]. These mortality benefits occurred even though no mortality effect was observed in either of the 2 pivotal trials that constituted approximately $50 \%$ of the weight in the meta-analysis. Moreover, the $95 \%$ confidence intervals reported in these 2 pivotal trials both excluded the risk ratios reported in the meta-analysis versus placebo and dobutamine, respectively. These observations suggest that the results of the meta-analysis were driven entirely by the 43 small-to-moderate sized studies which may be more susceptible to biases than larger, well-powered studies [2].

When evaluating the results of this meta-analysis to predict the results of future clinical trials, it interesting to note that the most profound mortality risk reduction reported in the 2012 meta-analysis occurred among cardiac surgery patients (risk ratio 0.52 [0.35-0.76], $\mathrm{p}=0.001$ )[2]. These findings, among others, contributed to the design and completion of the CHEETAH and LEVO-CTS trials, both of which were randomized, double-blind, placebocontrolled registration trials that evaluated the use of levosimendan among cardiac surgery patients [6-7]. Despite the optimistic estimates provided by meta-analyses, neither trial observed any effect on the primary outcome of 30-day mortality and the CHEETAH trial was ultimately halted due to futility. With the addition of the latest trials the findings of the prior meta-analyses are no longer valid, and the overall superiority of levosimendan is questioned.

The accompanying review also presents 3 recent studies in which patients received intermittent infusions of levosimendan for 6 or 24 hours at 2 to 4 week intervals [3-5]. While these studies do show favorable responses among levosimendan-treated patients, similar effects have also been reported with traditional inotropes (i.e. dobutamine [8]). Sufficiently large cohorts and/or controlled double-blinded comparisons between inotropes are lacking, making it difficult to determine whether or not these findings stem from the unique calcium sensitizing mechanism of levosimendan or may simply represent a safer approach to inotrope use that may be replicable with traditional inotropes.

In summary, there is reasonable room for caution when interpreting the overall evidence base describing the use of levosimendan in comparison with other inotropes. Whether the calcium-sensitizing mechanism of levosimendan is safer and/or more effective than conventional inotropes remains somewhat ambiguous. The extracts from hands-on tutorials sponsored by Orion Pharma, the maker of levosimendan, have been enthusiastically summarized in this review by the authors, who have also been for the most part investigators in Orion Pharma sponsored studies, as an aid for the use of levosimendan in advanced heart failure. What is known is that levosimendan improves cardiac output and relieves symptoms in patients with decompensated heart failure. In absence of large randomized controlled, and possibly double-blind, clinical trials we recommend a judicious rather than systematic use of levosimendan or of other inotropes in patients with advanced heart failure whose symptoms cannot be controlled with vasodilators and diuretics. 


\section{References}

1. Altenberger J, Gustafsson F, Harjola VP, Karason K, Kingden-Milles D, Kivikko M, Malfatto G, Papp A, Parissis J, Pollesello P, Polzl G, Tschope C. Levosimendan in acute and advamced heart failure: an appraisal of the clinical database and evaluation of its therapeutic applications. J Card Pharmacol. 2017

2. Landoni G, Biondi-Zoccai G, Greco M, Greco T, Bignami E, Morelli A, Guarracino F, Zangrillo A. Effects of levosimendan on mortality and hospitalization. A meta-analysis of randomized controlled studies. Crit Care Med. 2012; 40:634-46. [PubMed: 21963578]

3. Altenberger J, Parissis JT, Costard-Jaeckle A, Winter A, Ebner C, Karavidas A, Sihorsch K, Avgeropoulou E, Weber T, Dimopoulos L, Ulmer H, Poelzl G. Efficacy and safety of the pulsed infusions of levosimendan in outpatients with advanced heart failure (LevoRep) study: a multicentre randomized trial. Eur J Heart Fail. 2014; 16(8):898-906. [PubMed: 24920349]

4. Comin-Colet, J., et al. LION Heart Study Investigators. Multicenter, double-blind, randomized, placebo-controlled trial evaluating the efficacy and safety of intermittent levosimendan in outpatients with advanced chronic heart failure: the LION Heart Study. Paper presented at the European Society of Cardiology-Heart Failure Association Congress; Seville, Spain. 24 May, 2015;

5. García-González, MJ., et al. LAICA Study Investigators. Efficacy and security of intermittent repeated levosimendan administration in patients with advanced heart failure: a randomized, doubleblind, placebo controlled multicenter trial: LAICA study. Paper presented at the European Society of Cardiology-Heart Failure Association Congress; Florence, Italy. 21 May, 2016;

6. Mehta RH, Leimberger JD, van Diepen S, Meza J, Wang A, Jankowich R, Harrison RW, Hay D, Fremes S, Duncan A, Soltesz EG, Luber J, Park S, Argenziano M, Murphy E, Marcel R, Kalavrouziotis D, Nagpal D, Bozinovski J, Toller W, Heringlake M, Goodman SG, Levy JH, Harrington RA, Anstrom KJ, Alexander JH. LEVO-CTS Investigators. Levosimendan in Patients with Left Ventricular Dysfunction Undergoing Cardiac Surgery. N Engl J Med. 2017 May 25; 376(21):2032-2042. [PubMed: 28316276]

7. Landoni G, Lomivorotov VV, Alvaro G, Lobreglio R, Pisano A, Guarracino F, Calabrò MG, Grigoryev EV, Likhvantsev VV, Salgado-Filho MF, Bianchi A, Pasyuga VV, Baiocchi M, Pappalardo F, Monaco F, Boboshko VA, Abubakirov MN, Amantea B, Lembo R, Brazzi L, Verniero L, Bertini P, Scandroglio AM, Bove T, Belletti A, Michienzi MG, Shukevich DL, Zabelina TS, Bellomo R, Zangrillo A. CHEETAH Study Group. Levosimendan for Hemodynamic Support after Cardiac Surgery. N Engl J Med. 2017 May 25; 376(21):2021-2031. [PubMed: 28320259]

8. Nanas JN, Tsagalou EP, Nanas SN, Terrovitis JV, Tsolakis EJ, Toumanidis S, Papazoglou PD, Alexopoulos GP, Kanakakis J, Anastasiou-Nana MI. Reverse left ventricular remodeling by intermittent dobutamine infusions and amiodarone in end-stage heart failure due to idiopathic dilated cardiomyopathy. Int J Cardiol. 2006 Apr 4; 108(2):237-43. [PubMed: 16183152] 